Urban Water Systems \& Floods II 191

\title{
ESTIMATION OF FLOOD DAMAGE USING BUILDING GROUP INVENTORY AND MULTIDIMENSIONAL FLOOD DAMAGE ANALYSIS
}

\author{
DONG HO KANG, DONG HO NAM, SUK HO LEE \& BYUNG SIK KIM \\ Department of Urban and Environmental Disaster Prevention Engineering, \\ Kangwon National University, Republic of Korea
}

\begin{abstract}
As a result of the recent climate change, damage caused by local floods and typhoons has frequently occurred, and many lives and properties have been affected in the process. In particular, in the city center, much damage is set to occur because of river inundation. In this study, the flood damage area was calculated using the FLO-2D model, which is a flood inundation model, and the estimated flood damage amount was calculated by using a multidimensional flood damage analysis (MD-FDA). Through the FLO-2D model, flood damage area was calculated by flood inundation simulation by frequency (50, 80, 100, and 200 years). The flood damage rate for land use (residential, agricultural, and industrial) was calculated by overlapping flood damage area calculated using a geographic information system (GIS), a Wonju land use map, and an administrative district map. The flood damage rate is calculated using the area ratio according to the land use in the administrative district. However, in this study, flood damage rate is calculated using the flood damage rate proposed in the multidimensional flood damage analysis. Estimated flood damages by frequency were estimated using an estimated flood damage rate. In addition, the total damage amount was calculated by applying the damage rate of public facilities presented by the Ministry of National Land Construction of Japan. The results indicate that the flood damages estimated using area ratios were lower by up to $96 \%$ than those using building groups, and lower by $57 \%$ on average when the public facility damage rates were applied. Therefore, for analysis of flood damage using MD-FDA, building group-based damage estimation is recommended for residential and industrial areas.
\end{abstract}

Keywords: Flo-2D, multidimensional flood damage analysis, flood damage rate, flood damage.

\section{INTRODUCTION}

Recent changes in the environment and ecosystem caused by climate change and global warming have greatly increased the intensity of summer rainfall. In addition, the rapid urbanization has increased flood-prone areas with more residential areas and parks being built around rivers, which could contribute to massive losses of lives and property in urban areas in case flooding occurs. In fact, when typhoons, such as Rusa in 2002, Maemi in 2003, and Nari in 2004, struck South Korea, floods caused by heavy rains resulted in serious damage. To protect lives and property from repeated flooding and effectively manage such disasters, building an analysis system for forecasting is necessary. However, accomplishing this is difficult with the current information system, because most disasters have various variables and uncertainties [1]. The Intergovernmental Panel on Climate Change (IPCC) Fourth Assessment Report [2] forecasts that the global average annual temperature will increase by $6.3 \%$ at the end of the 21st century and more than seven million people could face flood damage annually in Asia if the annual average temperature increases by $3 \%$.

Hydrological issues, including flood and inundation analysis, require complex terrain analysis and flow prediction. These issues have been continuously studied using various methods such as numerical analysis programs and empirical equations.

To obtain the expected annual average damages in the flood control economic analysis, Gyudong [3] studied how to calculate the cost of damages for areas expected to be flooded 
by frequency and came up with an equation by collecting the data of the damages in areas that were flooded. Seung et al. [4] developed the multidimensional flood damage analysis (MD-FDA), an alternative to the flood control economic analysis that was widely used in Korea but had some problems. Keon Haeng et al. [5] applied the MD-FDA to the Dorimcheon basin with its flood damage estimation parameters adjusted for urban areas. Geun Sang and Jin Gyeg [6] attempted to address the limits of existing flood risk studies and developed a methodology to implement the MD-FDA based on the digital topographic maps and land cover maps of some sections of the Geum River. Keon Haeng [7] conducted a quantitative analysis of the benefits of preparing for climate change by estimating the flood damages of probable rainfall resulting from future climate change. Jeong Gi et al. [8] evaluated the flood-prone characteristics of Guri-si, Gyeonggi-do, Korea, through the MD-FDA based on geographic information system (GIS) data. To estimate the damage in flooded areas using the XP-SWMM model, Yong Hun et al. [9] reviewed the applicability of the MD-FDA in urban areas by taking into account the details of building shapes and contents.

Dutta and Heath [10] developed the flood damage assessment methodology (FDA) by linking property value data and flood models with GIS. Tate [11] established floodplain mapping using HEC-RAS and ArcView, and Snead [12] studied floodplain visualization using HEC-GeoRAS. The Water and Disaster Management Bureau of the Ministry of Land, Infrastructure, Transport and Tourism of Japan (MLIT [13] published the Manual on the Flood Control Economic Analysis and improved the methodologies contained in the existing Guideline on Flood Control Economic Analysis. Biza et al. [14] developed the Flood Analysis Toolbox (FAT), a flood damage assessment model that relates asset information, economic data, and hydrological data to GIS. Beffa and Connell [15] developed Hydro2de, a two-dimensional floodplain flow model, to review the topographical features and lattice generation conditions of lowland floodplain, which was applied to simulate floods in the Waihao River in New Zealand.

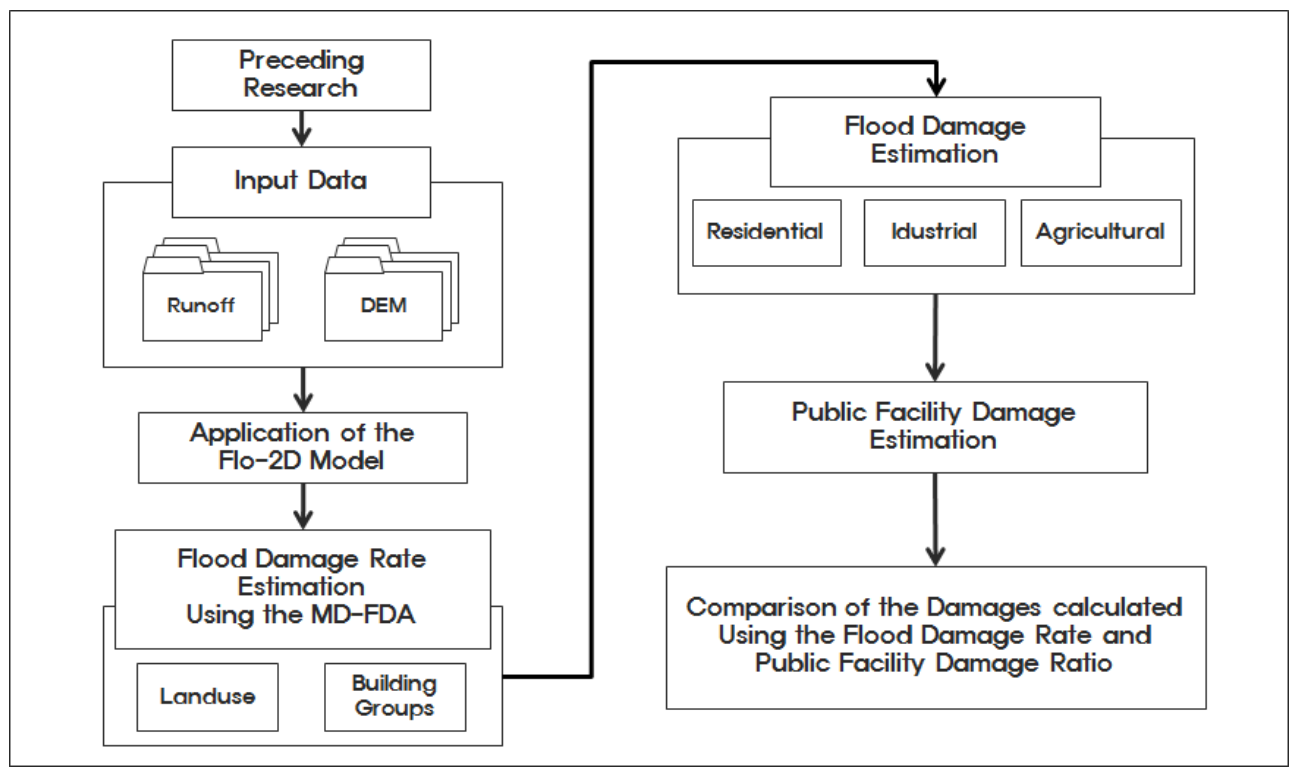

Figure 1: Study flow chart. 
In this study, the Wonju-cheon basin flowing through Wonju City was selected to calculate flood damage areas by frequency (50, 80, 100, and 200 years) using twodimensional flood model FLO-2D. We estimated the flood damage based on the MD-FDA and compared the flood damage calculated based on the area ratio with flood damage calculated using actual building group data. To estimate the flood damage in public facilities, we also compared the difference in damages calculated based on the public facility damage ratio described in Korea's Statistical Yearbook of Natural Disasters and the public facility damage ratio presented by Japan’s MLIT.

\section{THEORETICAL BACKGROUND}

\subsection{Multidimensional Flood Damage Analysis (MD-FDA)}

Forecasting flood damage is an important and sensitive issue in pushing forward with a flood control project because verifying the actual benefits of such project is difficult, not only before but even after its implementation. Both engineering and economic aspects should be considered to obtain reliable flood damage estimation. Thus, the scope of the analysis and investigation is broad. From an engineering perspective, flood simulation and flood forecasting are conducted using hydraulic and hydrological analyses, which are essential and fundamental steps in flood control planning, as well as flood damage assessment. On the economic side, diverse data and indicators that can represent the economic value of predicted flood areas are analysed and quantified as flood damage [16].

\subsection{Flood damage rate estimation method}

The flood damage rate refers to the ratio of the location data of spatial objects (i.e., geographic elements) overlapped by flood depth to the total so that the total asset value of the regional elements, such as housing, industry, and agriculture, can be converted into the asset value of the part within an administrative district that was flooded. Therefore, flood damage rates are calculated for each of the three regional elements of housing, industry, and agriculture by flood depth in an administrative district, and the sum of the flood damage rates by flood depth must always be 1. Fig. 2 shows the concept of overlapping the spatial information to estimate the flood damage rates.

\subsection{Public facility damage estimation method}

Estimating the damage to public facilities caused by a flood is almost impossible because of its massive range and magnitude. Therefore, the ratio of the civil engineering facility damage to the total asset damage is used. Table 2 shows the damage rates of public facilities of Japan's MLIT described in the Preliminary Feasibility Study of Water Resources Related Projects (4th edition) [17].

\subsection{Flood model Flo-2D}

The highly reliable FLO-2D model was developed by the Federal Emergency Management Agency (FEMA) in 1988 to identify the flood-prone areas in Colorado in the United States. The system consists of a processor for graphics editing and mapping and elements to simulate waterways and floodplains in detail. The grid developer system (GDS) creates the lattice grids of successive small tiles that represent the terrain. The FLO-2D model has parameters 
Table 1: Flood damage assets by administrative district based on the MD-FDA.

\begin{tabular}{|l|l|}
\hline Asset type & Assets \\
\hline Residential & $\begin{array}{l}\text { Building: residential buildings } \\
\text { Building content: home supplies }\end{array}$ \\
\hline Agricultural & $\begin{array}{l}\text { Farmland: fields and paddles } \\
\text { Produce: representative crops during flood season }\end{array}$ \\
\hline Industrial & $\begin{array}{l}\text { Tangible fixed/stored assets: production facilities and/or assets } \\
\text { except for land }\end{array}$ \\
\hline
\end{tabular}

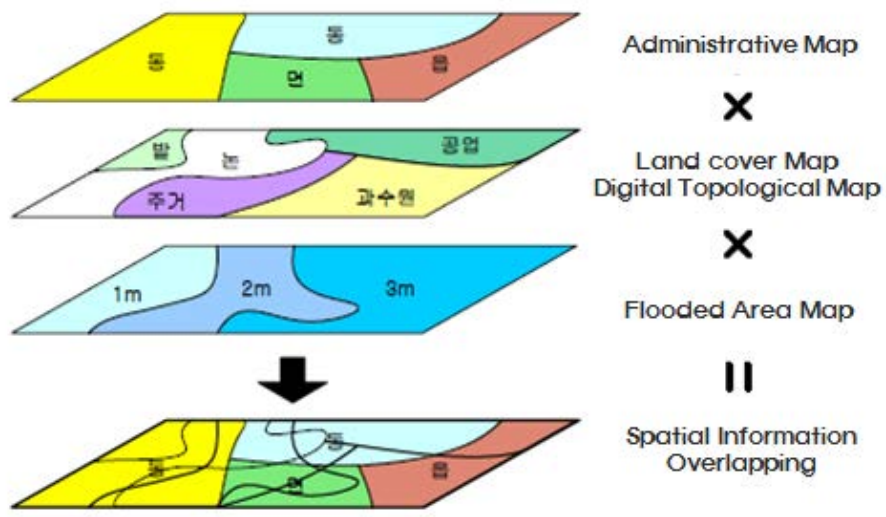

Figure 2: Spatial information overlapping for flood damage rate estimation.

Table 2: $\quad$ Flood damage ratios of asset types estimated by the MD-FDA. (Source: Manual on Flood Control Economic Analysis by the MLIT, Japan [13].)

\begin{tabular}{|c|c|c|c|c|c|c|c|c|}
\hline Facilities & Roads & Bridges & Sewerage & $\begin{array}{c}\text { Urban } \\
\text { facilities }\end{array}$ & $\begin{array}{c}\text { Public } \\
\text { facilities }\end{array}$ & Farmland & $\begin{array}{c}\text { Agricultural } \\
\text { facilities }\end{array}$ & $\begin{array}{c}\text { Sub } \\
\text { total }\end{array}$ \\
\hline $\begin{array}{c}\text { Damage } \\
\text { ratio }\end{array}$ & 0.616 & 0.037 & 0.004 & 0.002 & 0.086 & 0.291 & 0.658 & 1.694 \\
\hline
\end{tabular}

such as rainfall, flow in a channel, flow in a road, infiltration, and bank properties. The PROFILES program edits the slope and cross-sectional profile of the channel, and the flood path can be graphically illustrated on the MAXPLOT, MAPPER, and HYDRO. The flow equation of FLO-2D is shown in eqn (1) based on the continuity and momentum equations as follows:

$$
\begin{gathered}
\frac{\partial h}{\partial t}+\frac{\partial h V}{\partial x}=i \\
\mathrm{~S}_{\mathrm{f}}=\mathrm{S}_{0}-\frac{\partial \mathrm{h}}{\partial \mathrm{x}}-\frac{\mathrm{V}}{\mathrm{g}} \frac{\partial \mathrm{V}}{\partial \mathrm{x}}-\frac{1}{\mathrm{~g}} \frac{\partial \mathrm{V}}{\partial \mathrm{x}}=0
\end{gathered}
$$

where $h$ is the depth of the flow, $V$ is the mean flow rate of one of the eight directional flows (x direction) in the starting grid, and $i$ is the excess rain intensity. $S_{f}$ means the friction slope, which is based on the Manning equation. 


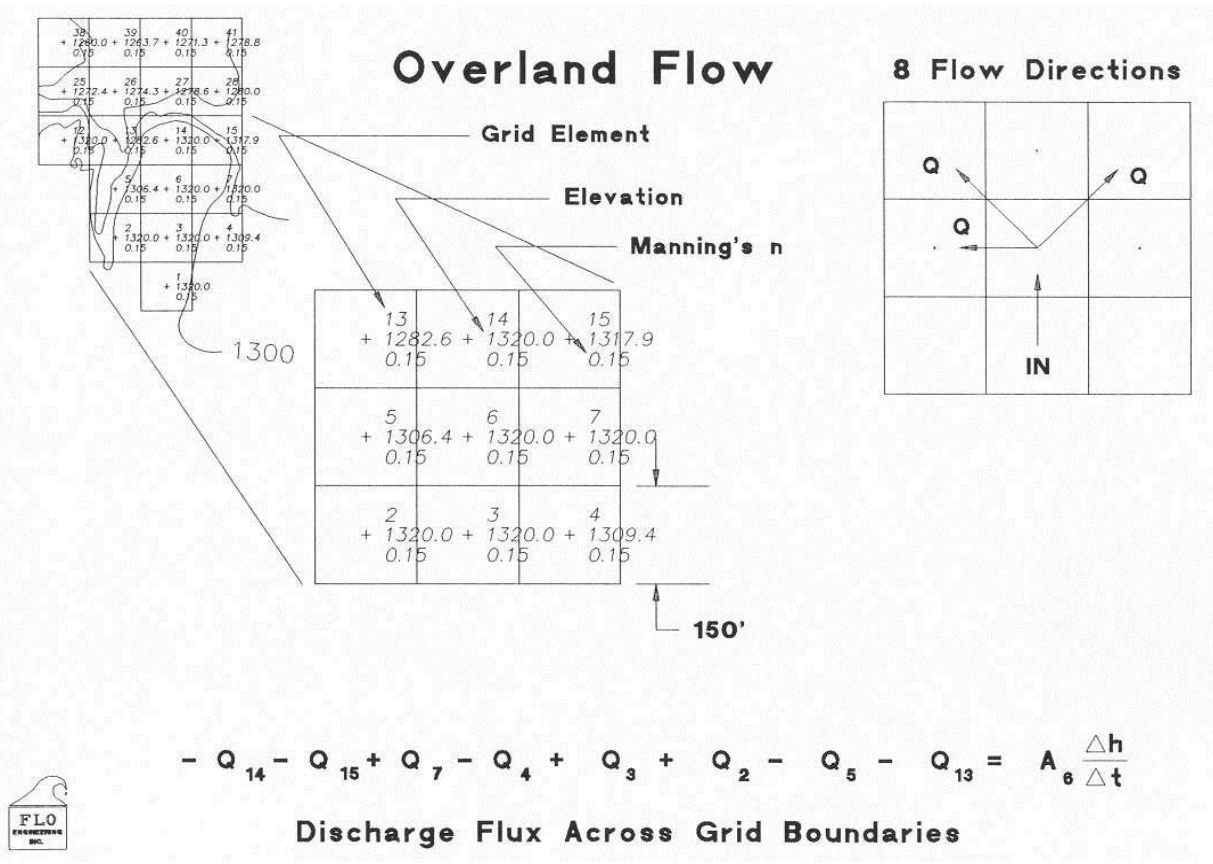

Figure 3: Flo-2D flow equation [18].

\section{INTRODUCTION AND APPLICATION OF THE STUDY BASIN}

\subsection{Study basin}

This study was conducted for the Wonju-cheon basin flowing across Wonju City. Wonjucheon, the first tributary of the Seom River, spans $29.08 \mathrm{~km}$, with a basin area of $152.93 \mathrm{~km}$, which accounts for about $10.26 \%$ of the Seom River basin. It originates from the Namtaebond peak of Chiaksan, which is located between Dunna-myeon, Hoengseong-gun, and Bongpyeong-myeon, Pyeongchang-gun, in Gangwon-do, and flows across Wonju and into the left bank of the Seom River. The Wonju-cheon basin is divided into an urban part and a mountainous part with similar areas because the stream runs across almost the center of the basin. According to the National River Maintenance Plan (1999), frequencies of 80 years for the downstream part and 50 years for the upstream part of the basin were reflected in the flood elevations. Therefore, in this study, the flood runoff was estimated for four frequencies of $50,80,100$, and 200 years.

\subsection{Input data}

The FLO-2D model requires runoff data and the digital elevation model (DEM). In this study, numerical maps in the scale of 1:5,000 were used.

For runoff estimation, the Francis formula was used. We simulated floods caused by the overflowing of the bank, not by its cracking. The simulation spot was selected based on the bank height and flood elevation by frequency (50, 80, 100, and 200 years) described in the Wonju-cheon Dam Feasibility Study [19]. 


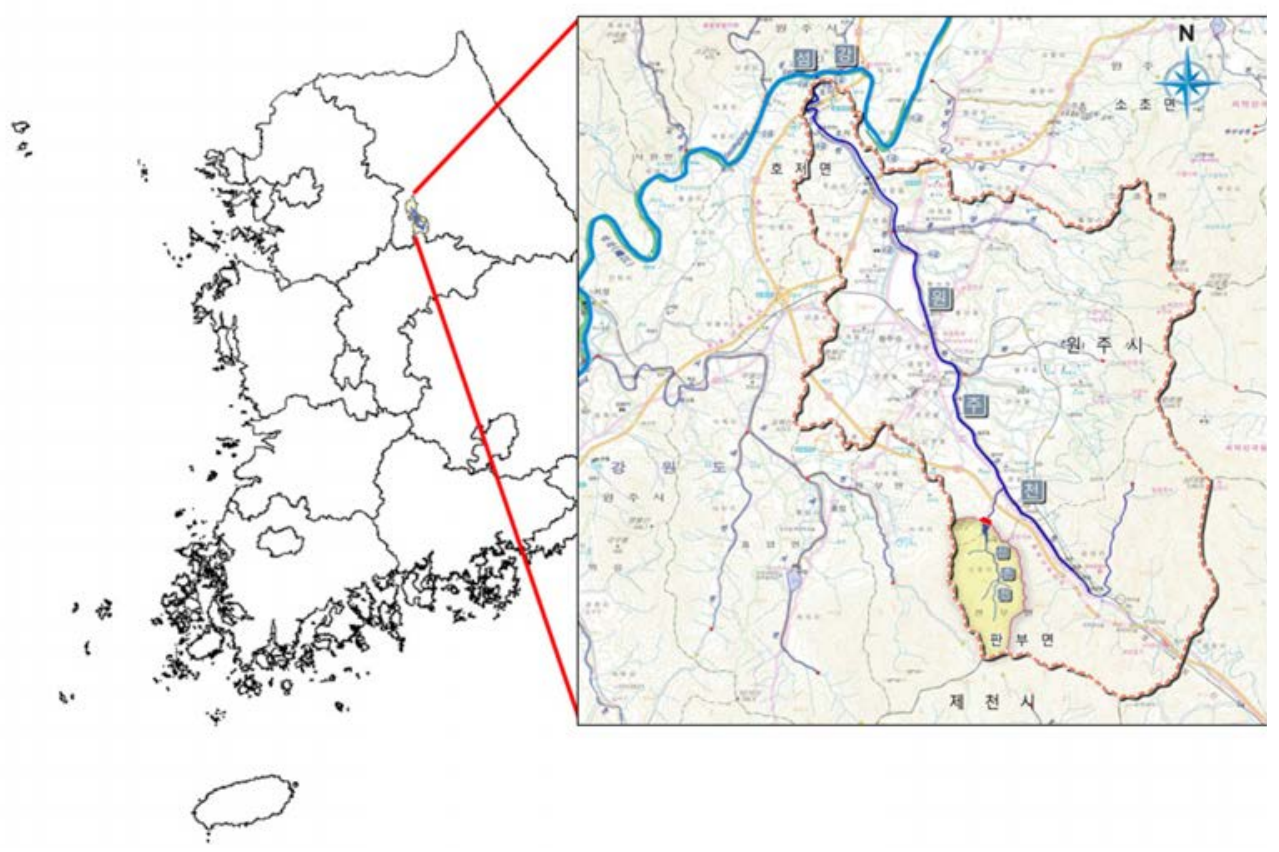

Figure 4: Wonju-cheon basin.

Table 3: Bank height, flood elevation, and overflow volume of the study area.

\begin{tabular}{|c|c|c|c|c|c|}
\hline Frequency & $\begin{array}{c}\text { Water level } \\
(\mathrm{m})\end{array}$ & $\begin{array}{c}\text { Bank height } \\
(\mathrm{m})\end{array}$ & $\begin{array}{c}\text { Overflow } \\
\text { height }(\mathrm{m})\end{array}$ & $\begin{array}{c}\text { Overflow } \\
\text { width }(\mathrm{m})\end{array}$ & $\begin{array}{c}\text { Overflow } \\
\text { volume }(\mathrm{cm})\end{array}$ \\
\hline 50 years & 107.959 & 107.14 & 0.819 & 50 & 68.01 \\
\hline 80 years & 108.12 & 107.14 & 0.98 & 50 & 89.01 \\
\hline 100 years & 208.2 & 107.14 & 1.06 & 50 & 100.19 \\
\hline 200 years & 108.42 & 107.14 & 1.28 & 50 & 132.89 \\
\hline
\end{tabular}

Table 4: Estimation of bank height, flood elevation, and over volume in the simulation spot.

\begin{tabular}{|c|c|c|c|c|}
\hline & \multicolumn{4}{|c|}{ Damage area(km $\left.{ }^{3}\right)$} \\
\cline { 2 - 5 } & 50 years & 80 years & 100 years & 200 years \\
\hline $\begin{array}{c}4-h r \\
\text { flooding }\end{array}$ & 4.77 & 6.16 & 6.64 & 6.74 \\
\hline
\end{tabular}

\subsection{Flood simulation using the Flo-2D model}

We estimated the flood elevation by frequency (50, 80, 100, and 200 years) in the simulation spot, simulated $4 \mathrm{hr}$ of flooding, and calculated the expected damage area and amount. 


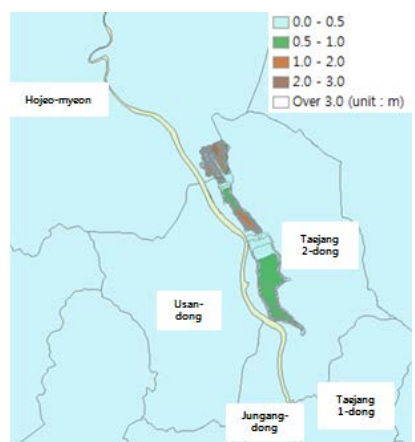

(a) 50 years

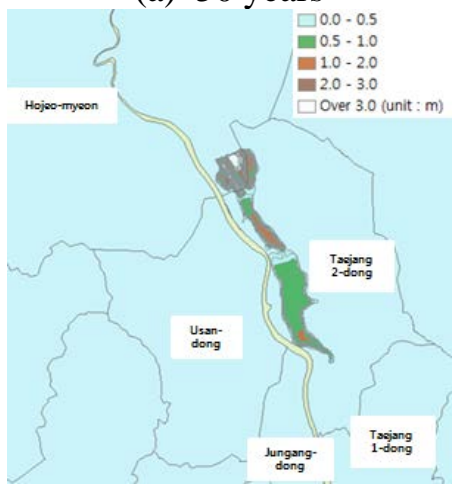

(c) 100 years

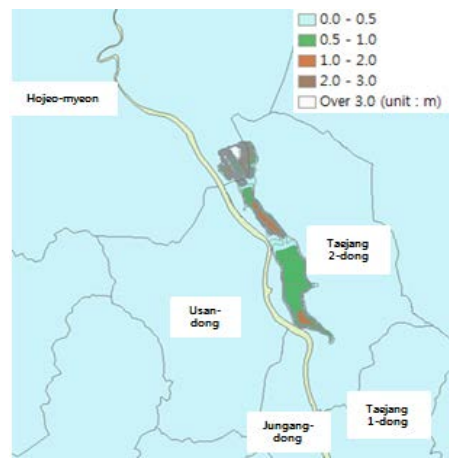

(b) 80 years

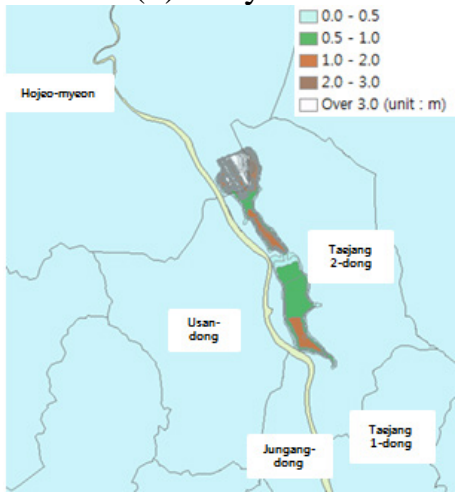

(d) 200 years

Figure 5: Damaged area by frequency.

\subsection{Estimation of the flood damage rate}

The method proposed by the MD-FDA suggests that, for agricultural areas, the flood damage rate should be calculated using their area ratios, whereas, for residential and industrial areas, the location information of spatial objects (building group) should be used. In reality, however, area ratio-based estimation is more frequently used because data collection on spatial objects is not easy. In this study, we attempted to compare the flood damage rates estimated using the two approaches (area ratios versus spatial objects' location information). The land use maps used in the analysis were taken from the National Land Use Map (2008) available at the National Spatial Data Infrastructure Portal website.

When the building group inventory was considered, the flood damage rate was estimated as the number of damaged buildings compared to the number of buildings plotted on the GIS.

However, when applying the area ratios, it was found that the residential and industrial areas tended to be expressed wider than the actual building areas on the land use map, which resulted in lower flood damage rates.

As shown in Fig. 7, the comparison indicates that the direct flood damage estimated using the building group damage rate with the frequency of 50 years is similar to that estimated using the previous damage rate. Moreover, the flood damages calculated based on the building group damage rates with the frequencies of 80,100 , and 200 years were higher than those estimated using the previous damage rates. 


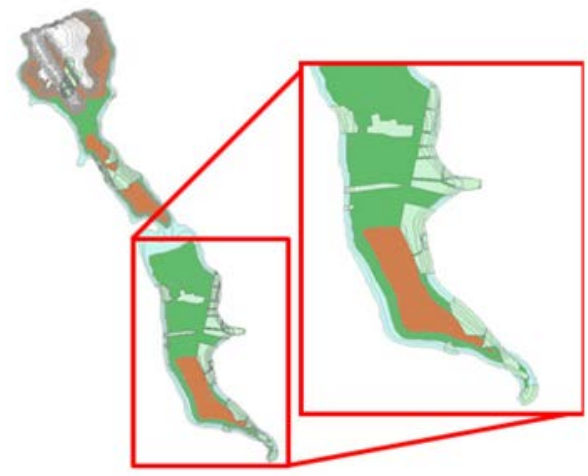

(a) Residential areas (area ratio).

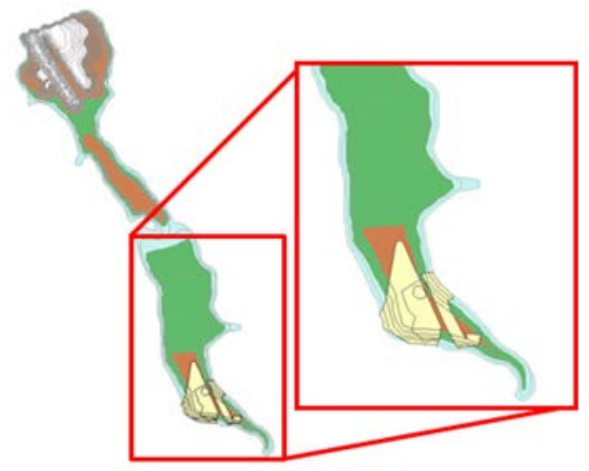

(c) Industrial areas (area ratio).

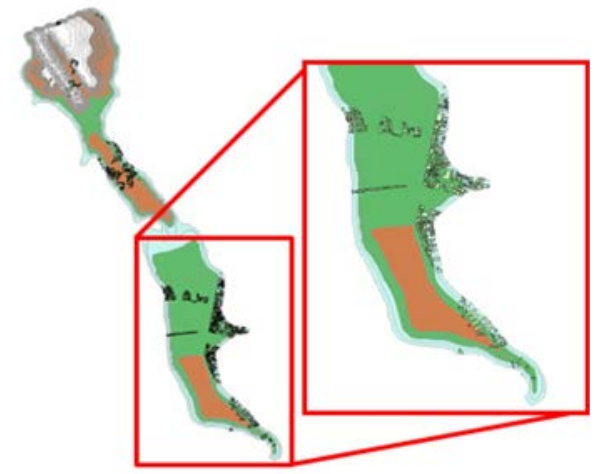

(b) Residential areas (building group).

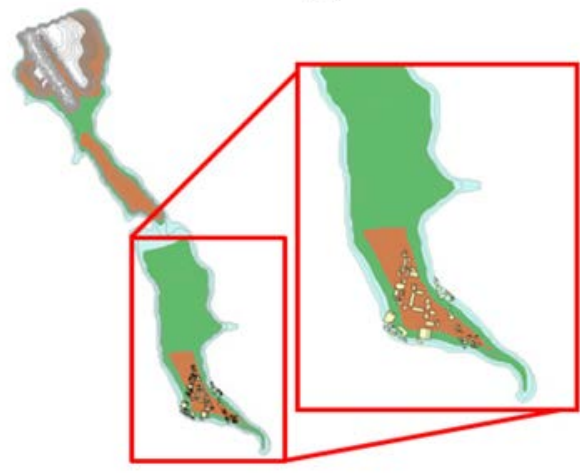

(d) Industrial areas (building group).

Figure 6: Comparison of area ratios and building groups.

\subsection{Estimation of the total flood damage}

Method 1, the existing damage estimation approach, employed the flood damage rate using area ratios and the public facility damage ratios of Japan's MLIT [13] described in the Preliminary Feasibility Study of Water Resources Related Projects (4th edition) [17]. Method 2 adopted the flood damage rates using the building inventory suggested by the MD-FDA and the public facility damage ratios of Japan's MLIT [13] described in the Preliminary Feasibility Study of Water Resources Related Projects (4th edition) [17]. The total damages obtained through the two methods were compared. In this study, the direct flood damage, except the loss of human lives, and the public facility damage were estimated, based on which the total damage considering the flood damage rate was calculated. Fig. 8 illustrates the total damages derived from the previous estimation method and the new method applied in this study. 


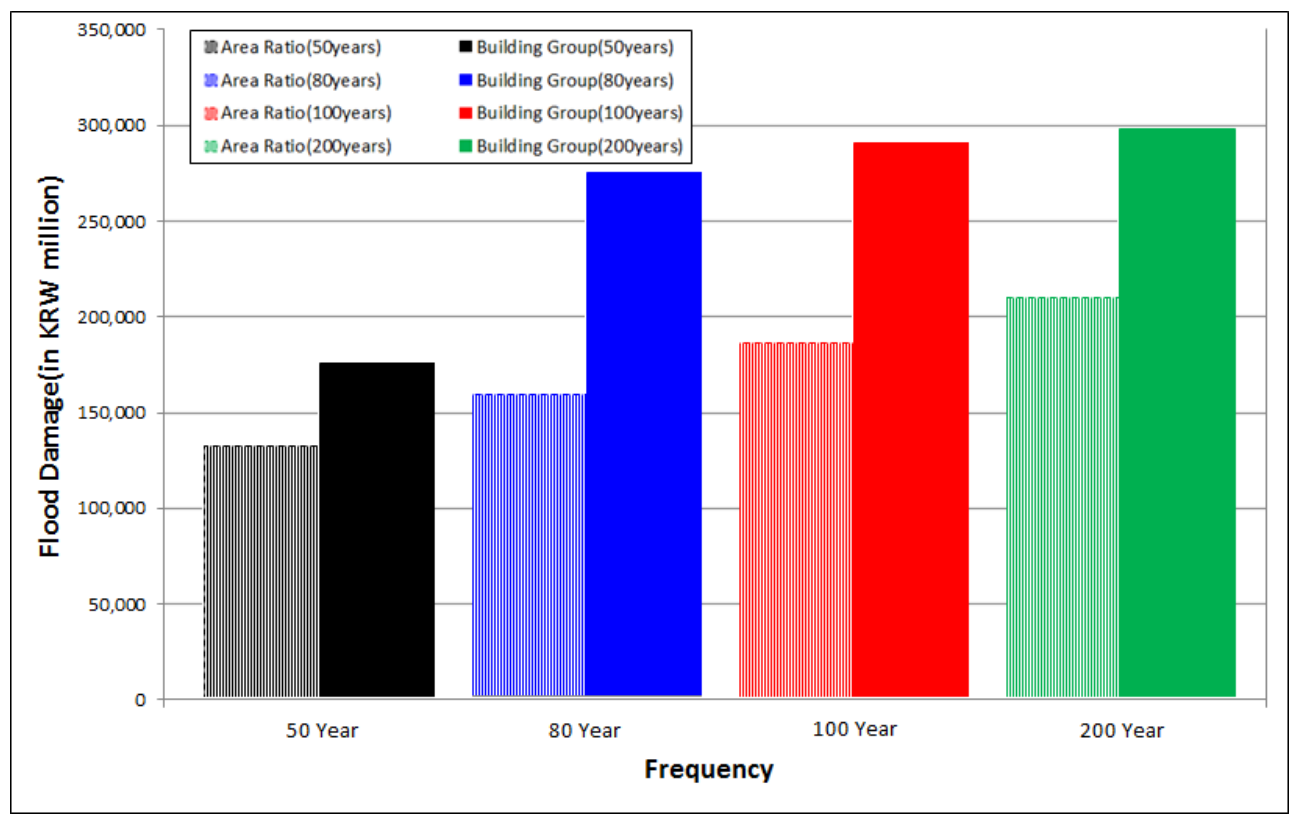

Figure 7: Comparison of direct flood damage according to estimation methods.

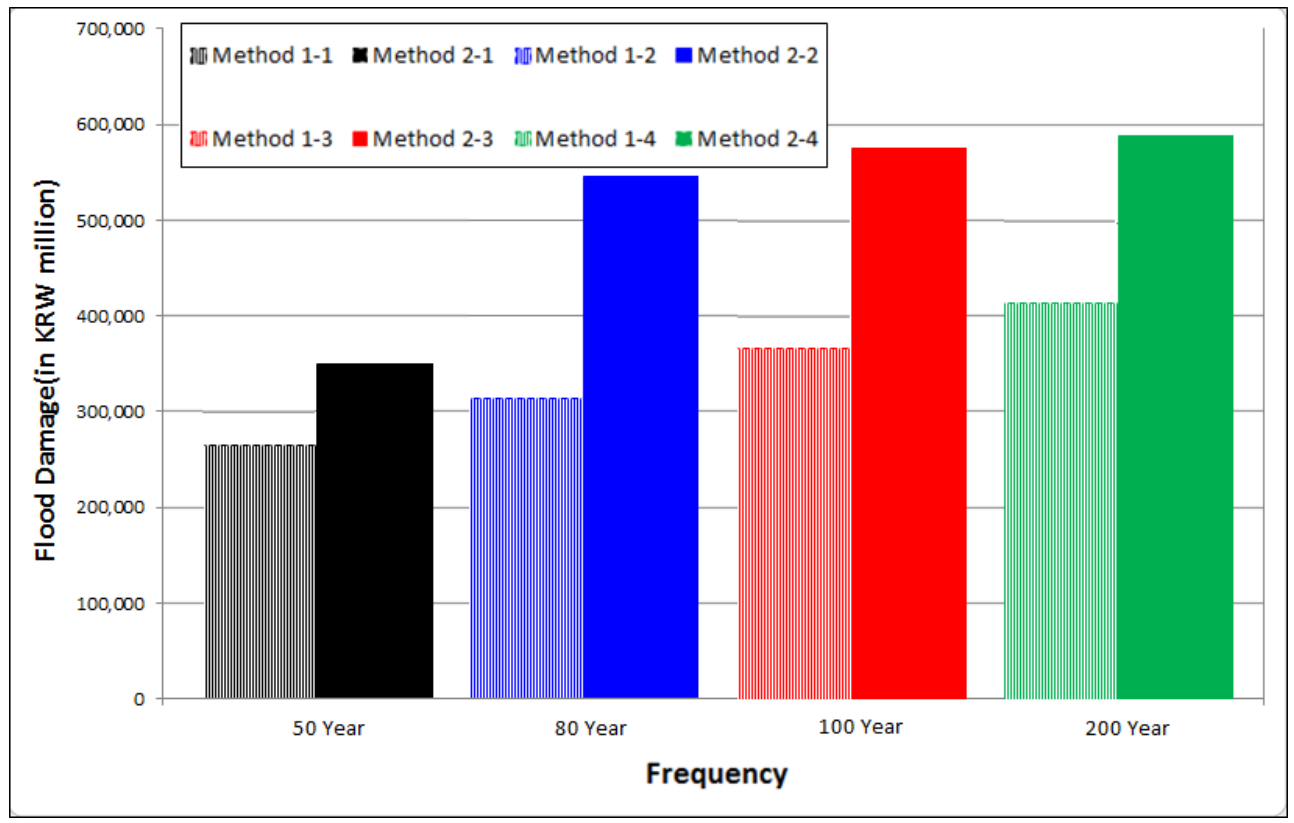

Figure 8: Comparison of the total flood damages estimated using the area ratio-based damage rate and the building inventory-based damage rate. 


\section{CONCLUSION}

This study used the MD-FDA to assess the direct flood damage estimated using different flood damage rate simulation methods (area ratio and building group inventory) and the total flood damage estimated by applying the public facility damage rate. Flood simulation was conducted for the urban Wonju-cheon basin by frequency $(50,80,100$, and 200 years) using the FLO-2D model. For flood damage rate estimation, the common area ratio-based method and a new approach of using the actual building group inventory were applied. Afterward, the results of the general asset damage were compared. For the total damage estimation, public facility damage rates of Japan's MLIT described in the Preliminary Feasibility Study of Water Resources Related Projects (4th edition) [17] were applied.

1. Flood damage was analyzed using two flood damage rate estimation methods based on a) the area ratio of the flooded area to the land used and b) the building group inventory. The comparison of the two methods showed that the flood damage rates obtained using the building group-based method were higher than those obtained using the area ratio-based approach. The estimation of the direct damages based on the aforementioned flood damage rates indicated that the damage rates obtained using the area ratio-based method lower than those obtained using the other method by 32\%-96\%.

2. For public facility damage estimation, the results of applying the public facility damage rates suggested by Japan's MLIT were compared. The public facility damages estimated by the area ratio-based damage rates were lower by an average of $57 \%$.

In previous studies, potential flood areas were used to estimate the final flood-damaged area. However, in this study, we analyzed the expected flood damage areas by frequency using flood models, which are expected to be used to develop countermeasures against floods and eventually help reduce flood damage in the future.

When the building group inventory was considered, the flood damage rate was estimated as the number of damaged buildings compared to the number of buildings plotted on the GIS. However, when applying area ratios, it was found that the residential and industrial areas tended to be expressed wider than the actual building areas on the land use map, which resulted in lower flood damage rates. Calculating the general asset damages and public facility damages using the area ratio-based damage rate and the building group inventorybased damage rate showed that the total damages estimated by the former method were smaller than the latter. As more building group inventories have recently been established nationwide, and the MD-FDA requires the building group-based method for residential and industrial areas, using building group inventories rather than area ratios is recommended to estimate flood damages.

\section{ACKNOWLEDGEMENT}

This research was supported by a grant [2017-MPSS31-004] from Supporting Technology Development Program for Disaster Management funded by Korean Ministry of Public Safety and Security(MPSS).

\section{REFERENCES}

[1] Yun, H.C., Min, K.S. \& Kim. M.G., Construction of multi-purpose hazard information map based on digital image using geospatial information. Journal of the Korean Association of Geographic Information Studies, 13(3), pp. 91-101, 2010.

[2] IPCC, Climate Change 2007: The Physical Science Basis. Contribution of Working Group I to the Fourth Assessment Report of the Intergovernmental Panel on Climate Change, eds S. Solomon, D. Qin, M. Manning, Z. Chen, M. Marquis, K.B. Avery, M. Tignor \& H.L. Miller, Cambridge University Press: Cambridge and New York, 2007. 
[3] Gyudong, Y., A study on estimation method of expected flood damage considering local characteristics. Master's thesis, Inha University, 2003.

[4] Seung, A.C., Choong, S.Y., Myung, P.S. \& Hung, S.K., Multi-dimensional expected flood damage assessment method: Principle and procedure. KSCE Journal of Civil Engineering, 10, pp. 839-843, 2004.

[5] Keon Haeng, L., Seung An, C., Hung Soo, K. \& Myung Pil, S., Application of multidimensional flood damage analysis for urban flood damage. KSCE Journal of Civil Engineering, 26(4), pp. 363-369, 2006.

[6] Geun Sang, L. \& Jin Gyeg, P., Flood damage assessment according to the scenarios coupled with GIS data. Journal of the Korean Society for Geo-spatial Information Science, 19(4), pp. 71-80, 2011.

[7] Keon Haeng, L., Estimation of expected flood damage considering uncertainty and under climate change. Doctor's thesis, Inha University, 2011.

[8] Jeong Gi, P., Gi Sung, C. \& Geun Sang, L., Evaluation of flood damage assessment of Guri city based on GIS. The Korean Society for Geospatial Information Science, 5, pp. 169-170, 2015.

[9] Yong Hun, T., Young Do, K., Boo Sik, K. \& Mun Hyun, P., Application of multidimensional flood damage analysis in urban area. Journal of Korea Water Resource Association, 50(6), pp. 397-405, 2017.

[10] Dutta, D. \& Heath, S., Benefits of flood mitigation in Australia, Bureau of Transport and Regional Economics Report 106, 1998.

[11] Tate, E., Floodplain Mapping and Terrain Modeling Using HEC-RAS and ArcView GIS, 1999.

[12] Snead, D., Floodplain Visualization Using HEC-Geo RAS, 2000.

[13] Ministry of Land Infrastructure and Transport and Tourism, Manual on Flood Control Economic Analysis, 2000.

[14] Biza, P., Gimu, V., Christian, H. \& Smith, G., The Use of a GIS-based Software Tool for Benefit-Cost Analysis of Flood Mitigation Measures in the Czech Republic, DHI Software Conference: DHI Software, 2001.

[15] Beffa, C. \& Connell, R.J., Two-dimensional flood plain flow. I: model description, Journal of Hydrological Engineering, ASCE, 6(5), pp. 397-405, 2001.

[16] Chung Seong, Y., Decision making model for most preferable alternative in basinwide flood damage reduction planning. Doctor's thesis, Inha University, 2007.

[17] Korea Development Institute, Modification and supplementary study of the preliminary feasibility study standard guide for water resources (dam) project (4th ed.), 2008.

[18] Flo-2D Software, Flo-2D PRO Reference Manual, 2005.

[19] K-Water, Wonju-cheon Dam Feasibility Study Report, 2015. 